\title{
Octreotide Acetate
}

National Cancer Institute

\section{Source}

National Cancer Institute. Octreotide Acetate. NCI Thesaurus. Code C53447.

The acetate salt of a synthetic long-acting cyclic octapeptide with pharmacologic properties mimicking those of the natural hormone somatostatin. Octreotide is a more potent inhibitor of growth hormone, glucagon, and insulin than somatostatin. Similar to somatostatin, this agent also suppresses the luteinizing hormone response to gonadotropin-releasing hormone, decreases splanchnic blood flow, and inhibits the release of serotonin, gastrin, vasoactive intestinal peptide (VIP), secretin, motilin, pancreatic polypeptide, and thyroid stimulating hormone. 